\title{
Location Patterns of Restaurants in Istanbul*
}

\author{
Hatice Ayatac, Vedia Dokmeci \\ Istanbul Technical University, Faculty of Architecture, Urban and Regional Planning Department, Istanbul, Turkey \\ Email: ayatachatice@gmail.com,vediadokmeci@gmail.com
}

How to cite this paper: Ayatac, H., \& Dokmeci, V. (2017). Location Patterns of Restaurants in Istanbul. Current Urban Studies, 5, 202-216. https://doi.org/10.4236/cus.2017.52012

Received: April 6, 2017

Accepted: June 27, 2017

Published: June 30, 2017

Copyright $(9) 2017$ by authors and Scientific Research Publishing Inc. This work is licensed under the Creative Commons Attribution International License (CC BY 4.0).

http://creativecommons.org/licenses/by/4.0/

\begin{abstract}
Dining out plays an important role for the residents of the post-modern day Istanbul in terms of recreational purposes. The location of restaurants reflects the impacts of the transformation of the city's cultural life on the urban structure. This paper investigates the spatial distribution of restaurants in Istanbul between 1997 and 2013. Over this period of time, while the number of restaurants has increased in all of the concentric zones in the city, their ratio has decreased in the core and in the intermediate zones, while it has increased in the periphery, especially in the sub-centers. In this paper, regression analysis was used to investigate the spatial distribution of restaurants. The number of restaurants was taken as the dependent variable, and the socio-economic characteristics of the districts and the distance from the sea coast were taken as the independent variables. The results of the study reveal that, in 1997, the relation between the number of restaurants and population, GNP/pc and the distance from the sea shore had a significant effect on the location of restaurants. In 2013, however, population has become less influential and income has become more significant due to the economic growth in the periphery of the metropolitan area. This is the consequence of the multi-center development of the city, the suburbanization of higher income groups to a certain extent and the increase in the consumption services on account of multiculturalism arising from globalization.
\end{abstract}

\section{Keywords}

Location, Restaurants, Spatial Analysis, Service Sector, Istanbul

\section{Introduction}

After the 1980s, dining out became one of the most popular forms of recreation in Istanbul as a reflection of the conspicuous consumption characteristics of post-modern culture which is already claimed by Finkelstein (1989). During this

*The article analyzes and compares the location of restaurants; reflects the impacts of the transformation of the city's cultural life on the urban structure in Istanbul between 1997 and 2013. 
period, the rapid increase in the number of restaurants was also the result of the population increase and economic development, globalization and the liberalization policies implemented in the Turkish economy (Tokatli \& Boyaci, 1997). Globalization can involve many processes, such as the changing spatial structure of economic activities, migration of capital, mobility of goods, and the spread of values and norms to various parts of the world. The influence of foreign cultures may lead to changes in the character of cities and culture (Robertson, 1995; Van Kempen \& Marcuse, 1997; Zukin, 1998; Jackson, 2004). Internet, TV and boosting tourism provided the means for the diffusion of different cultures. Global economic and cultural influences result in multiculturalism, and consequently increase the variety in food services and lead to the emergence of an international taste (Erkip, 2003). Not only international influence but also rural migration altered the taste preferences and eating behavior, and thus the location of these facilities in Istanbul. This paper investigates the growth and spatial distribution of restaurants in Istanbul in parallel to the transformation of the city over time.

In Europe, eating out has increased eating styles that have changed as a result of post-modern culture (Jacobs \& Scholliers, 2003). In their research, Riley (1994) and Warde et al. (1999) address the cultural changes in consumption in detail. Attention to lifestyles has given rise to new, highly visible consumption spaces, such as "nouvelle cuisine" restaurants, and coffee bars (Zukin, 1998). The study conducted by Wood (1992) offers a brief analysis of the latest issues in the cultural context of food and eating as they apply to dining out and demonstrates the importance to everyday life of the hospitality industry in terms of consumption, employment and environmental issues. The food service industry exemplifies two aspects of post-modern consumer culture: according to Peacock (1992), it is flexible, artisan-focused and context-dependent enough to offer a high degree of customization. Thus, it can provide an ultimately short-lived fashion product in a highly simulated environment: typical criteria of post-modernism (Jameson, 1984). At the same time, this industry represents the most routine operationalization of service, which according to Ritzer (1996) is the other face of post-modern consumer society.

The paper authored by Warde and Marten (1998) is a sociological study of eating out in the UK. It isolates a number of features that distinguish sociological perspectives from market research approaches to the issue. It presents a practical focus to the study of consumer behavior in order to ensure compromise in understanding. At the lowest level of urban land use activities; restaurants, movie theaters or shops selling similar products/services are clustered within the urban center (Anas et al., 1998: p. 1440). Holm et al. (1995) present an in-depth analysis of retailing (including food services) in Scandinavia with a focus on the general trends in population, households and employment.

Nayga and Wanzala (1996) present a national-level analysis of customer expenditures and price distribution in the USA. In the USA, in the early 1980s, over 90 percent of all Americans have dined at a fast food restaurant while more than 53 percent have eaten at a McDonald's alone in a month (Smith, 1985). 
According to more recent figures, almost 83 percent of the consumers in the USA visited quick-service restaurants, and just over 68 percent visited casual dining restaurants at least once a week in 2013 (US Statistics). Austin et al. (2005) used cluster analysis and explored the location patterns of such restaurants, and suggested that fast-food restaurants are concentrated within a short walking distance from schools, exposing children to poor-quality food in the neighborhood where they attend school. The shopping center food service providers typically cluster together in food courts (Reimers \& Clulow, 2004). There are also studies that investigate the spatial distribution by taking into consideration the competitive location of fast-food restaurants in a city (Thomadsen, 2007). Jones et al. (1999) presented that restaurants consist of $15.5 \%$ of commercial activities in Fort Worth in Dallas, USA. Smith (1983) examined two aspects of the restaurant industry in Canada: national pattern of restaurant development and the tendency to dine out, and local patterns are described and possible processes influencing these patterns identified. In another study, Smith (1985) investigated the locational patterns of five categories of restaurants in eight Canadian cities in Ontario to identify spatial regularities. The tendency to agglomerate or deglomerate among restaurants in the same category and in different categories; spatial correlations with other land uses; apparent effects of varying levels of traffic on the location of restaurants, and variations in restaurant patterns in cities with different populations were among the spatial regularities investigated. Smoyer-Tomic et al. (2008) examined whether exposure to supermarkets and fast food outlets differs by varying socioeconomic status at the neighborhood level in Edmonton, Canada. For fast food outlets, the odds of exposure were greater in areas with more renters, lone parents, low-income households, and public transportation commuters; and lower among those with a higher median income and dwelling value.

Simmons and Kamikihara (1999) claim that although eating out it is not as common as North America, there is an enormous "entertainment" industry serving business, based on restaurants and bars, which provides $12 \%$ of total employment-dwarfing finance and real estate- and $20 \%$ of stores, in the metropolitan area of Nagoya, Japan. Axenov et al. (1997) elaborated on the impact of the change from the complete dominance of administrative regulation into the market forces on the spatial distribution of retail trade and consumer services in St. Petersburg. This results in the emergence of a new city system comprised of private business activity within the historical center and a number of linear and local gravity centers outside the historical core.

The available literature on food service comprises of different characteristics for analysis; for example, Nayga and Capps (1994) relate the demand for different types of restaurants to different socio-economic segments, while Binkley (1998) demonstrates that demographic and economic differences have less effect on demand than the population density in metropolitan areas.

The literature on restaurants is extensive; however, it rarely addresses loca- 
tional dynamics due to the fact that such information is usually considered proprietary (Pillsbury, 1987). The preceding studies that prove to be the most useful provide an overall contextual setting of the restaurant industry, especially in terms of location strategies, problems, and growth patterns encountered by previous types of restaurant chains (Belasco, 1979; Helphand, 1983; Langon, 1985). They also provide an overview of this industry that changes rapidly (McDonald, 1983; Gu, 2002; Han \& Ryu, 2009). In his research, Pillsbury (1987) illustrated that accessibility, locational ambiance, and demographic profile of the target population are the primary locational considerations although a variety of perceptual, psychological, and spatial elements are significant for particular types of restaurants and situations in Atlanta, USA. Mushinski and Weiler (2002) analyzed the geographic interdependencies, the relationship between the number of establishments in a certain place and the neighboring market areas as well as demand-oriented eating and drinking establishments in eight states in the United States.

Location and economic factors seem to be as important as the attributes of the food and the service (Binkley, 1998); however, they did not draw much attention from researchers. In addition, although there are several studies in developed countries on account of the fact that the food industry constitutes an important part of the service economy; investigation on their location pattern is usually neglected. The purpose of this paper is to explore the full range of restaurants in Istanbul by using regression analysis with respect to the socio-economic characteristics of districts in order to understand the mechanics of the location of restaurants over time. In the second section, demographic and socio-economic conditions, and their spatial distribution are explained. Regression analysis of the relationship between the number of restaurants, and the demographic and socio-economic characteristics of districts are presented in section three. Finally, concluding remarks and suggestions for further research are provided in the final section.

\section{Population Growth and Socio-Economic Characteristics of Istanbul}

Istanbul is the most densely populated metropolitan area in Turkey, and it was home to 14,377,018 residents in 2014 (TurkStat, 2014). In addition, it is the largest market, one of the wealthiest urban areas, and the most important tourist attraction in the country on account of the fact that it has been the capital of three different empires over centuries. Istanbul also hosts the vast majority of company headquarters and financial institutions, and it is scene to a significant share of trade and business service activities. It is not only the cultural and educational center but also international trade hub in Turkey. High population growth and the construction of bridges and peripheral highways stimulated the growth of multi-center development of the city (Dokmeci \& Berkoz, 1994). In the 1960s, the vast majority of jobs were concentrated in the core of the city. Following the expansion of the city in the 1970s, however, a new spatial structure has emerged 
in the city: a structure in which population and employment increasingly decentralized in a close relation with the CBD where sub-centers of employment and commerce were formed primarily in the intermediate zone. This outlook is best illustrated by the fact that employment in the service sector in the core of the city decreased from $54.0 \%$ to $33.1 \%$ between 1970 and 1985, while it increased from $32.5 \%$ to $51.4 \%$ in the intermediate zone, and from $13.5 \%$ to $15.5 \%$ in the periphery. In 2002, employment in the service sector slumped further to $14.5 \%$ in the core, decreased to $40.9 \%$ in the intermediate zone, while it reached $45.6 \%$ in the periphery. Population growth was the basis for much of the growth in the market. Consequently, retail and consumer service activities in Istanbul were obliged to operate in a market that was driven largely by population expansion, but it also had to respond to a significant fluctuation in purchasing power. Much of the growth and change in retail and consumer service activity has therefore occurred in response to the deconcentrating market. An important characteristic of the market growth is that the inner city is well-served by bus, streetcar, and rapid transit and the intermediate zone enjoys reasonable level of service, whereas the periphery is not well-served except for metro access to some extent and few bus lines that provide access to the city core.

Thus, the growth in retail and consumer services in the periphery has occurred in an environment that is largely automobile-oriented. Retail and consumer service activities have gone through a number of phases of development over the course of the growth of metropolitan areas. The downtown core has been the traditional commercial heart of the urban area. As population increased, the decentralization of the market, which constrained in the same location up to the 1970s according to the availability of public transport, was accompanied by the decentralization of commercial and consumer services along major arterials, giving rise to the retail strips that remain a feature of the historical core. In the post-1970s, multi-center development was accompanied by the emergence of air-conditioned malls, which became the competitors of the shopping streets accompanied by entertainment and consumer services. This process of reorganization was also observed in the distribution of income. As a result of the disproportionate concentration of national income in Istanbul and the increased exposure to other cultures, higher income groups proved to be the basis of a new consumer culture and a life style influenced by global consumption and recreation patterns (Tokatli \& Boyaci, 1999). Bosporus and the Marmara Sea shores became attractive for higher income neighborhoods (Dokmeci \& Berkoz, 2000) as well as their service areas such as restaurant clusters. However, higher income neighborhoods were also built within the forests in the north of the city. Squatter settlements mostly spread around the industrial areas in the periphery or in the intermediate zone of the city. Currently, there are intensive urban renewal projects in the squatter settlements in order to provide better and healthy urban environments. Multi-center development of the urban structure led to decay in the inner city, and the changes in population density affected the spatial distribution of the need and demand for services (Dokmeci \& Berkoz, 1994). 
The revitalization of old neighborhoods as well as the construction of new neighborhoods, bridges and peripheral highways altered land prices, and thus the distribution of land uses within the city.

Consequently, demographic, socio-economic, physical and cultural transformation of Istanbul is reflected in the distribution of consumer services such as restaurants in different zones. Although the number of restaurants in Istanbul grew from 7888 in 1997 to 12,456 in 2013, their distribution presents different patterns. To be more specific, it decreased from $26.5 \%$ to $13.5 \%$ in the city core and from $45.5 \%$ to $26.5 \%$ in the intermediate zone, while it increased from $28 \%$ to $58 \%$ in the periphery. This trend is almost identical to the decrease of employment in the service sector in the core and the intermediate zone, and its simultaneous increase in the periphery. However, the number of restaurants has increased in all of the zones. The analysis of the distribution of restaurants by districts demonstrates that in 1997, Kadikoy with the highest income and modern lifestyle hosted the highest number of restaurants, while in 2013, Fatih had the highest number of restaurants due to the fact that it was merged with Eminönü which hosts the old CBD of Istanbul and which is located at the intersection of different transportation lines. In 1997, Beyoğlu, which was the old CBD of Istanbul, was host to the second highest number of restaurants (Dokmeci \& Berkoz, 1994); however, in 2013, it receded to the fourth rank as a consequence of the multi-center development in the city. However, it sustained its character as the major entertainment center of the city throughout the history despite the tremendous growth of the city during the second half of the century (Dokmeci \& Ciraci, 1999). The old CBD Eminönü, which ranked third in 1997, made it up to the first rank after it was merged with Fatih. While in 1997, Bakirkoy, which is among the most affluent neighborhoods and one of the most popular districts in the city with its modern urban character, was ranked fourth (Dokmeci \& Berkoz, 2000), in 2013, it receded to the ninth rank due to the split of the district. As a modern district very well served with alternative transportation lines, Sisli was ranked sixth in 1997, while in 2013, it reached the third rank on account of its thriving role as the new CBD of Istanbul (Dokmeci \& Berkoz, 1994). While in 1997, Besiktas was at the seventh place, it was ranked fifth in 2013 due to its increased importance as a sub-center and a transportation hub as well as the high rate of students and higher income residents living in the district. Sariyer, which enjoys the amenities and higher socio-economic characteristics of its location along the Bosporus, was ranked eighth in 1997; however, it descended to the 13th rank as a consequence of the fact that squatter settlements that were previously at lower ranks (such as Umraniye, Bahçelievler and Sancaktepe) advanced higher in the list as they enjoyed a higher rate of population increase in comparison to Sariyer as the new sub-centers. The ranking of the restaurants in the remainder of the districts presents a lower profile toward the periphery of the city given that population density and income per capita are lower.

In general, three basic strategies in terms of the location of restaurants can be 
identified. Basic restaurants tend to be located along highly accessible corridors, in retail cores and along shopping streets. The rate of change for each cluster is a function of locational costs (rents and other fixed costs of remaining business), and the location's intrinsic attitude towards change.

In the next section, the findings of the regression analysis that was performed in order to reveal the relationship between the distribution of restaurants, and the socio-economic characteristics and distance from the coast in each of the districts will be presented.

\section{Regression Analysis of Spatial Distribution of Restaurants in Istanbul}

The distribution of restaurants is the product of a complex interaction between the traditional and non-traditional location factors (Pillsbury, 1987). Over the history, although local residents of the city did not have the habit of eating out, the core of Istanbul was always host to different types of restaurants along with entertainment facilities operated by the minority groups, under the influence of different cultures due to having an international port. In Istanbul, the majority of restaurants were traditionally located in the historical CBD as a consequence of the Westernization movement in the 19th century (Dokmeci \& Ciraci, 1999), which was greatly influenced from Paris where restaurants were part of the urban life at that time (Appelbaum, 2011). Another factor that made a significant impact on eating habits of the residents of Istanbul was the White Russian migrants who moved to Istanbul during the October Revolution in 1917 (Dokmeci \& Ciraci, 1990; Deleon, 1995). During the second half of the 20th century, a great number of migrants, who moved to Istanbul as a result of industrialization, led to a change in eating habits as well as the location and type of restaurants to a great extent (Yaprakli \& Keser, 2010). Furthermore, in the post-modern era, farmers who lost their jobs due to the decrease in agricultural production as a result of the free trade policy and workers who lost their jobs due to the shutdown of factories continued to migrate to big cities in search of employment (Yazgi et al., 2014). In such cities that grew rapidly and developed economically, restaurants proved to create employment opportunities for the migrants bringing in new eating cultures to these cities, which resulted in the rapid increase in the number and type of restaurants. Finally, the most important change in eating habits and the location of restaurants occurred as a result of globalization and post-modernism due to conspicuous consumption characteristics and the impact of international food chains. During this period, not only the number of restaurants increased but also the establishments occupied sidewalks wherever possible, which is a Mediterranean characteristic that is not common in the local culture. In addition, the rapid increase in the number of shopping malls in line with the multi-center development of the city also contributed to the decentralization of restaurants.

The selection of the location of a restaurant is based on a variety of behavioral factors including but not limited to the attractiveness of the restaurant image, 
the spatial behavioral patterns of the consumers, public utilities, clusters of competitors' location, and local amenities (Min, 1987). A comprehensive review on the consumer studies in food industry is provided by Johns and Pine (2002). In their review, they identify areas of communality within the subject as well as gaps and weaknesses in the body of knowledge on consumer behavior in the food industry. According to Haynes and Fotheringham (1984), emphasis on the importance of the relative location concept, in practice the effect of competitive restaurant location on the customers' spatial behavior seems to be substantial given the fact that under normal circumstances restaurants draw higher attraction from customers when a higher number of competitors are located nearby. This may be explained by the fact that customers are more attracted to many closely-located homogenous restaurants due to the fact that such a situation can offer them a relatively higher number of options (such as the opportunity to find the most favorable price, quality and services). For the purposes of this analysis, tied restaurants including university, office building and hospital cafeterias and grills, hotel and motel restaurants that primarily serve their own guests, and restaurants in primate clubs were excluded because their presence at a given location are tied to their viability.

In this paper, regression analysis was used to explore the spatial distribution of restaurants by taking into consideration not only the population, GNP (TurkStat, 1996) and the economic development index (Istanbul Chamber of Commerce, 2011) but also the distance from the sea shore of each district. The population size was taken as a variable for the analysis of spatial distribution of restaurants since it has a direct effect on the CBD retail visits and an indirect effect on the location of restaurants. Economic level was taken as a variable due to the fact that it indicates whether households can afford to eat out especially in a developing country such as Turkey. Distance from the sea shore was taken as another variable since Istanbul is surrounded by sea, and it is expected that restaurants will be located on the sea shore in order to capitalize on the advantages it offers. The number of restaurants was obtained from the Istanbul Chambers of Restaurants. The spatial distribution of restaurants by districts in 2013 is shown in (Figure 2). It is evident that the restaurants are mostly clustered together in certain areas. Some of the clusters are located in highly visible sites including the CBD, regional malls, road junctions adjacent to highways, and along shopping streets such as Bagdat Boulevard in Kadikoy.

The results of the regression analysis for the year 1997 are presented in Table 1 , and the results for the year 2013 can be found in Table 2 .

According to the results of the regression analysis performed for the year $1997, \mathrm{GNP} / \mathrm{pc}$ had more impact on the number of restaurants as it was suggested in other studies (McCracken \& Brandt, 1987; Mihalopoulos \& Demoussis, 2001) in comparison to population and distance from the sea coast. The reason behind this may be that eating out was still an activity for the higher-income back then, and thus restaurants were mostly located along the coast of the Bosporus where 
Table 1. Results of the regression analysis of the relationship between the number of restaurants and the characteristics of the districts for 1997.

\begin{tabular}{cccc}
\hline Variables & $\beta$ & $\mathrm{T}$ & Sig. T \\
\hline Population & 0.666 & 3.833 & 0.002 \\
GNP/pc (TurkStat, 1996) & 0.636 & 3.714 & 0.002 \\
Distance from the sea coast & -0.459 & -2.777 & 0.015 \\
\hline
\end{tabular}

$\mathrm{R}^{2}=0.672 ;$ Adj. $\mathrm{R}^{2}=0.602 ; \mathrm{F}=9.571 ;$ Sig. $=0.01 ; \mathrm{N}=18$.

Table 2. Results of the regression analysis for 2013.

\begin{tabular}{cccc}
\hline Variables & $\beta$ & $\mathrm{T}$ & Sig. T \\
\hline $\begin{array}{c}\text { Population } \\
\text { Econ. Dev. Index (2011) } \\
\quad \begin{array}{c}\text { Istanbul Chamber of } \\
\text { Commerce, 2011) }\end{array}\end{array}$ & 0.304 & 3.867 & 0.000 \\
Distance from the sea coast & -0.761 & 8.426 & 0.000 \\
\hline
\end{tabular}

$\mathrm{R}^{2}=0.790 ;$ Adj. $\mathrm{R}^{2}=0.772 ; \mathrm{F}=48.823 ;$ Sig. $=0.000 ; \mathrm{N}=39$.

higher income residents preferred in order to benefit from the advantages it offered.

The results of the regression analysis performed for the year 2013 indicate that the impact of economic development index has become more influential on the number of restaurants as the case is in other studies (McCracken \& Brandt, 1987; Mihalopoulos \& Demoussis, 2001) in comparison to population, while distance from the sea shore did not have a great effect on the number of restaurants per district. In addition, the explanation of the variables which were taken for 2013 (Adj. $\mathrm{R}^{2}=0.77$ ) was higher than that for 1997 (Adj. $\mathrm{R}^{2}=0.60$ ). Over the last decade, the increase in personal income played an important role in this outlook.

Thus, the Bosporus lost its attractiveness due to the increase in the population of the city and the economic development among the residents with lower income who moved to the middle-income neighborhoods in the periphery together with the fact that upper-income households moved to the suburbs and other cultures asserted greater influence in terms of dining-out. These restaurants served their interest by selling international values along with local cuisines from different parts of the country both to the rich and to the poor and, in doing so, helped to establish the hegemonic status of the middle class in post-modern society. In these new rich neighborhoods, disposable income has become the basis for cultural power. In recent years, the increase in the number of women in the workforce, the number of single individuals and the feeling of loneliness in a rapidly growing city also affected the number of restaurants. In addition, clustering in mega-malls located in the new sub-centers is a new trend for the location of restaurants.

\section{Conclusion}

The majority of the restaurants in Istanbul were traditionally located in the his- 
torical CBD under the influence of the Westernization movement, which largely affected the lifestyle in the 19th century. Another important factor that had influence on eating habits and on the location of restaurants was the great number of White Russians in-migration during the WWI following the October Revolution. Later on, in the second half of the 20th century, the influx of migrants from rural areas due to the transformation of the economy not only led to the modification of the urban structure of the cities but also affected the prevalent eating habits and the location and type of restaurants that featured local cooking practices from different parts of the country. Finally, globalization and post-modernism had tremendous influence on consumption habits and spaces by offering alternative individual choices fashioned a vibrant market of urban restaurants that accommodate different tastes and manners for different social classes. In addition, the multi-center development of the city and increasing number of shopping malls increased the number of restaurants and led to the agglomeration of restaurants.

Agglomeration has become the most dominant element of the dynamics in the location of restaurants over the last two decades. The corporatization of the industry in general and the thriving fast-food sector as a global pillar in eating behavior have been mainly responsible for such a trend. Significant initial investments and high overhead costs together with massive campaigns in order to expand to hundreds of new locations per year within larger companies required standardization of all elements of the food chain in order to maintain control.

In this paper, regression analysis was used to investigate the relationship between the number of restaurants and the characteristics of districts and the distance from the sea coast for the years 1997 and 2013. First of all, the spatial distribution of the population and the service sector in the core, the intermediate zone and in the periphery were illustrated for both 1997 (Figure 1) and 2013 (Figure 2). Then, growth of the retail and consumer service growth due to the increasing use of automobile-oriented transportation was explained. Although the number of restaurants has increased in all of the concentric zones between 1997 and 2013, their ratio has decreased in the core and in the intermediate zone, and it increased in the periphery by almost $50 \%$ in parallel to the trends observed in the population and the service sector. In addition, the increasing number of single individuals, the increase in the number of women in the workforce, and the feeling of loneliness in a large city that grows rapidly contributed to the increase in the number of restaurants. Moreover, keeping up with Jones trend also stimulated the habit of eating out even for the residents in the lower income group.

For the regression analysis, the number of restaurants was taken as a dependent and population, economic characteristics and distance from the sea shore were taken as independent variables. According to the results, in 1997, population and economic level were more influential on the number of restaurants in comparison to distance from the sea coast. On the other hand, it was observed that in 2013, economic level was more important than population; however, 


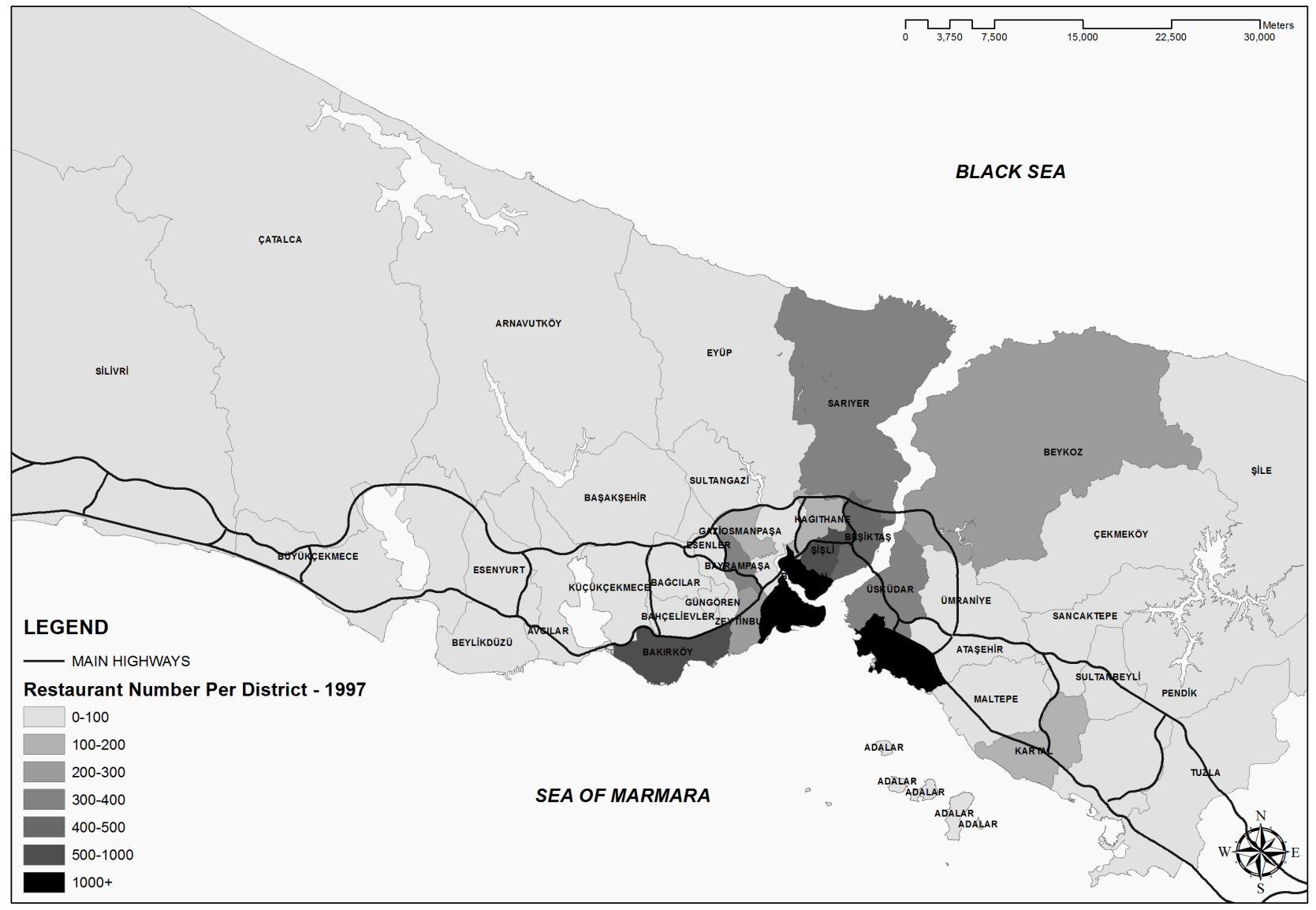

Figure 1. The spatial distribution of restaurants in Istanbul in 1997.

distance from the sea shore was not a significant factor that affected the number of restaurants. The reason behind this may be the growth of population and economic development in the periphery as well as suburbanization of the higher income group, which led the sea coast to lose its attractiveness to some extent.

Moreover, people with different tastes and cultures who came from different parts of the country together with international influences led to a very vibrant market comprising of urban restaurants very promising but risky for investors.

This study contributes to the available literature on the location and evolution of restaurants in metropolitan areas by considering the development of restaurants as a spatial diffusion process modeled with regression analysis. Morphologically and in terms of the processes at work, the string feature of the boom in the earlier 21 st century, especially in light of our examination of the previous periods, illustrates the difference between the coastal and peripheral developments. In light of this difference, three factors deserve specific mention. First, Istanbul's periphery is rapidly developing with the construction of large housing projects that are served by mega malls with large food courts. Second, the availability of large plots at the edge of the metropolitan area eased the resolution of the problems related to site assembly for large developments, which were served by the peripheral highways. Thirdly, more fancy restaurants were located along the Bosporus, where a higher number of higher income residents live, rather than 


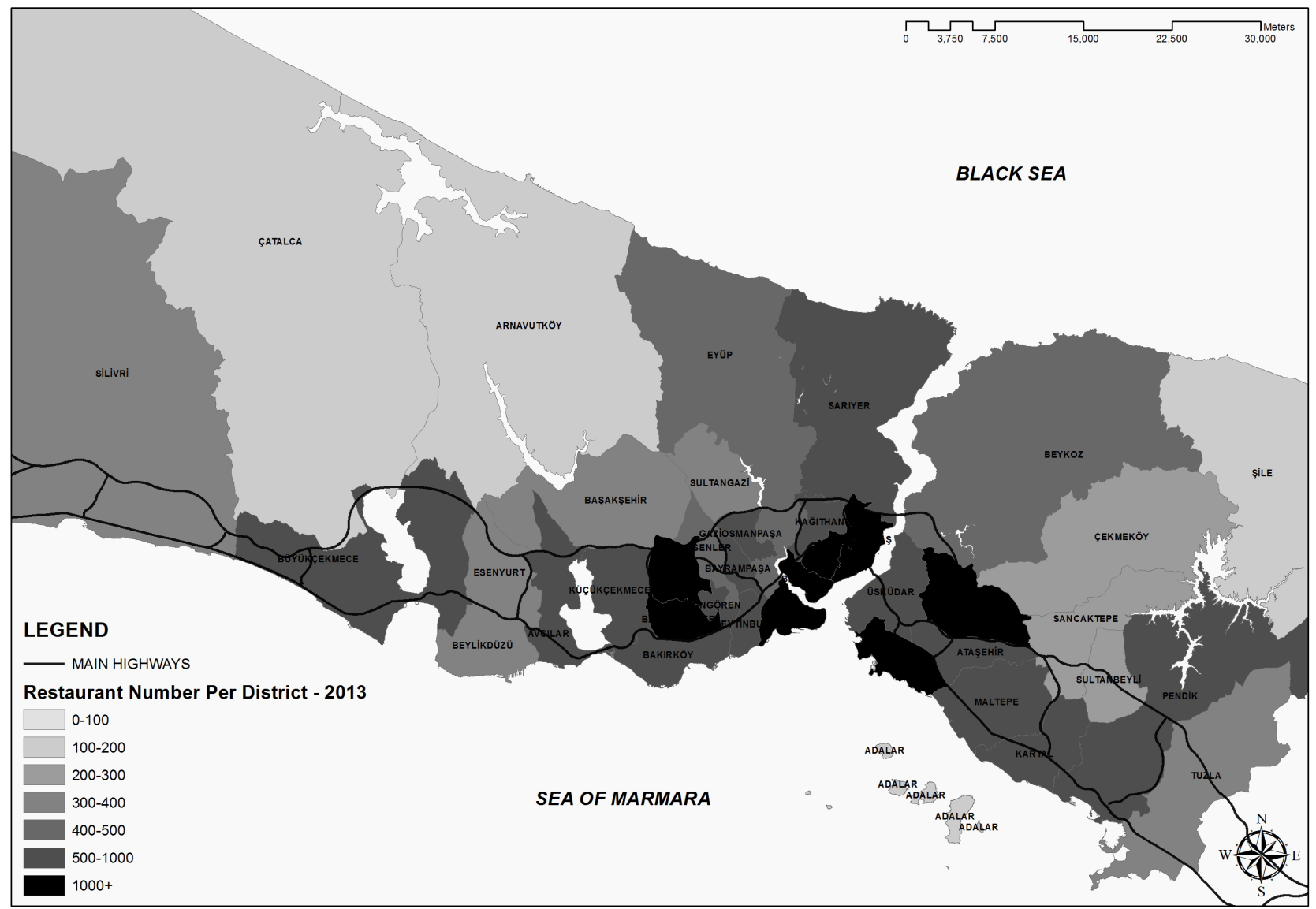

Figure 2. The spatial distribution of restaurants in Istanbul in 2013.

the periphery. Fourthly, the restaurants in the historical core mainly aim at serving tourists and businessmen. On the one hand, restaurants clustered in a certain location seem to enjoy a high volume of customers; on the other hand, clustering causes bankruptcy of the restaurants that fail to compete with others. Therefore, there is a high rate of takeover among these.

The results of the study will be useful for urban and regional planners, policymakers, investors and marketing consultants. Investigating the socio-psychological aspects of restaurant location by paying due attention to the needs and behavior of different social groups in the post-modern society is suggested for further research.

\section{References}

Anas, A., Amott, R., \& Small, P. (1998). Urban Spatial Structures. Journal of Economic Literature, 26, 1426-1464.

Appelbaum, R. (2011). Dishing It Out: In Search of the Restaurant Experience. London: Reaktion Books.

Austin, S. B., Mely, S. J., Patel, A., Sanchez, B. N., Gortmaker, S. L., \& Buke, S. (2005). Clustering of Fast-Food Restaurants around Schools: A Novel Application of Spatial Statistics to the Study of Food Environment. American Journal of Public Health, 95, 1575-1581. https://doi.org/10.2105/ajph.2004.056341

Axenov, K. E., Bondarchuck, E., \& Brade, I. (1997). The New Retail Trade and Services 
and Their Emerging Location Patterns in St. Petersburg, GeoJournal, 42, 403-417. https://doi.org/10.1023/A:1006818217194

Belasco, W. J. (1979). Toward a Culinary Common Denominator: The Rise of Howard Johnson's, 1925-1940. Journal of American Culture, 2, 503-519. https://doi.org/10.1111/j.1542-734X.1979.0203_503.x

Binkley, J. K. (1998). Demand for Fast Food across Metropolitan Areas. Journal of Restaurant and Foodservice Marketing, 1, 37-50. https://doi.org/10.1300/J061v03n01_03

Deleon, J. (1995). The White Russians in Istanbul. Istanbul: Remzi.

Dokmeci, V., \& Berkoz, L. (1994). Transformation of Istanbul from a Monocentric to a Polycentric City. European Planning Studies, 2, 193-205. https://doi.org/10.1080/09654319408720259

Dokmeci, V., \& Berkoz, L. (2000). Residential-Location Preferences According to Demographic Characteristics in Istanbul. Landscape and Urban Planning, 48, 45-53.

Dokmeci, V., \& Ciraci, H. (1990). Beyoglu. Istanbul: Turing.

Dokmeci, V., \& Ciraci, H. (1999). From Westernization to Globalization: An Old District of Istanbul. Planning History, 21, 13-23.

Erkip, F. (2003). The Shopping Mall as an Emergent Public Space in Turkey. Environment and Planning A, 35, 1073-1093. https://doi.org/10.1068/a35167

Finkelstein, F. (1989). Dining Out: A Sociology of Modern Manners. New York, NY: New York University Press.

Gu, Z. (2002). Analyzing Bankruptcy in the Restaurant Industry: A Multiple Discriminant Model. International Journal of Hospitality Management, 21, 25-42.

Han, H., \& Ryu, K. (2009). The Roles of the Physical Environment, Price Perception, and Customer Satisfaction in Determining Customer Loyalty in the Restaurant Industry. Journal of Hospitality \& Tourism Research, 33, 487-510. https://doi.org/10.1177/1096348009344212

Haynes, K. E., \& Fotheringham, A. S. (1984). Gravity and Spatial Interaction Models. Beverly Hills, CA: Sage Publication.

Helphand, K. (1983). The Landscape of McDonald's. In M. Fishwick, \& B. Green (Eds.), Ronald Revisited: The World of Ronald McDonald (pp.39-44). Green, OH: Bowling Green University Popular Press.

Holm, F., Falkebo, M., Salmiovirta, T., Ramstad, A. H., \& van Rooy, H. (1995). Analysis of Retailing in the Nordic Countries. International Trends in Retailing, 12, 3-31.

Istanbul Chamber of Commerce (2011). Economic Development Index.

Jackson, P. (2004). Local Consumption Cultures in a Globalizing World. Transactions of the Institute of British Geographers, 29, 165-178.

https://doi.org/10.1111/j.0020-2754.2004.00123.x

Jacobs, M., \& Scholliers, P. (2003). Eating Out in Europe: Picnics, Gourmet Dining and Snacks since the Late Eighteenth Centuries. Oxford/New York, NY: Berg.

Jameson, F. (1984). Postmodernism or the Cultural Logic of Late Capitalism. New Left Review, 146, 53-92.

Johns, N., \& Pine, R. (2002). Consumer Behavior in the Food Service Industry: A Review. International Journal of Hospitality, 21, 119-134.

Jones, K., Kamikihara, \& Simmons, J. (1999). Dallas Fort Worth: Commercial Structure and Change. In M. Yeates (Ed.), Metropolitan Commercial Structure and the Globalization of Consumer Services, Progress in Planning (50, Part 4, pp. 273-290).

Langon, P. (1985). Burgers! Shakes! The Atlantic, 256, 74-89. 
McCracken, V. A., \& Brandt, J. A. (1987). Household Consumption of Food-away-fromHome: Total Expenditure and by Type of Food Facility. American Journal of Agricultural Economics, 69, 274-284. https://doi.org/10.2307/1242277

McDonald, K. (1983). The Commercial Strip: From Main Street to Television Road. Landscape, 27, 12-19.

Mihalopoulos, V. G., \& Demoussis, M. P. (2001). Greek Household Consumption of Food away from Home: A Microeconomic Approach. European Review of Agricultural Economics, 28, 421-432. https://doi.org/10.1093/erae/28.4.421

Min, H. (1987). A Multi-Objective Retail Service Location Model for Fast-Food Restaurants, OMEGA. International Journal of Management Sciences, 15, 429-441.

Mushinski, D., \& Weiler, S. (2002). A Note on the Geographic Interdependencies of Retail Market Areas. Journal of Regional Science, 42, 75-86.

https://doi.org/10.1111/1467-9787.00250

Nayga, R. M., \& Capps, O. (1994). Impact of Socio-Economic and Demographic Factors on Food away from Home Consumption: Number of Meals and Type Facility. Journal of Restaurant and Foodservice Marketing, 1, 45-69. https://doi.org/10.1300/J061v01n02_04

Nayga, R. M., \& Wanzala, M. N. (1996). Food away from Home Expenditures in the United States: A County Level Analysis. Journal of Restaurant and Foodservice Marketing, 1, 39-51. https://doi.org/10.1300/J061v01n03_03

Peacock, M. (1992). Towards a New Consumer. International Journal of Hospitality Management, 11, 301-304.

Pillsbury, R. (1987). From Hamburger Alley to Hedgerose Heights: Toward a Model of Restaurant Location Dynamics. Professional Geographer, 39, 326-344. https://doi.org/10.1111/j.0033-0124.1987.00326.x

Reimers, V., \& Clulow, V. (2004). Retail Concentration: A Comparison of Spatial Convenience in Shopping Strips and Shopping Centers. Journal of Retailing and Consumer Services, 11, 207-221.

Riley, M. (1994). Marketing Eating Out: The Influence of Social Culture and Innovation. British Food Journal, 96, 15-18. https://doi.org/10.1108/00070709410072463

Ritzer, G. (1996). The McDonaldization of Society. Thousand Oaks, CA: Pine Forge Press.

Robertson, R. (1995). Globalization Time-Space and Homogeneity and Heterogeneity. In M. Featherstone (Ed.), Global Modernities (pp. 61-86). London: Sage.

Simmons, J., \& Kamikihara, S. (1999). Nagoya: Commercial Structure and Change. In M. Yeates (Ed.), Metropolitan Commercial Structure and the Globalization of Consumer Services, Progress in Planning (50, Part 4, pp. 233-252).

Smith, S. L. J. (1985). Location Patterns of Urban Restaurants. Annals of Tourism Research, 12, 581-602.

Smith, S. T. J. (1983). Restaurants and Dining Out: Geography of a Tourism Business. Annals of Tourism Research, 10, 515-545.

Smoyer-Tomic, K. E., Spence, J. C., Raine, K. D., Armhein, C., Cameron, N., Yasenovskiy, V., Cutumisu, N., Hemphill, E., \& Healy, J. (2008). The Association between Neighborhood Socioeconomic Status and Exposure to Supermarkets and Fast Food Outlets. Health and Place, 14, 740-754.

Thomadsen, R. (2007). Product Positioning and Competition: The Role of Location in the Fast Food Industry. Marketing Science, 26, 792-804.

https://doi.org/10.1287/mksc.1070.0296 
Tokatli, N., \& Boyaci, Y. (1997). Internationalization of Retailing in Turkey. New Perspectives on Turkey, 17, 97-128. https://doi.org/10.1017/S0896634600002776

Tokatli, N., \& Boyaci, Y. (1999). The Changing Morphology of Commercial Activity in Istanbul. Cities, 16, 181-193.

TurkStat (1996/2014). Turkish Statistical Instititute, Ankara. www.turkstat.gov.tr

Van Kempen, R., \& Marcuse, P. (1997). A New Spatial Order in Cities? American Behavioral Scientists, 41, 285-298. https://doi.org/10.1177/0002764297041003002

Warde, A., \& Marten, L. (1998). Eating Out and the Commercialization of Mental Life. British Food Journal, 100, 147-153. https://doi.org/10.1108/00070709810207513

Warde, A., Martens, L., \& Olsen, V. (1999). Consumption and the Variety: Cultural Omnivorusness, Social Distinction and Dining Out. Sociology, 33, 105-127. https://doi.org/10.1177/S0038038599000061

Wood, R. C. (1992). Dining Out in the Urban Context. British Food Journal, 94, 3-5. https://doi.org/10.1108/00070709210022064

Yaprakli, T. S., \& Keser, E. (2010). According to Product Groups, the Effects of Global Consumer Culture and Ethnic Identity on Consumption Habits: An Application to Turkey. The Journal of International Social Research, 9, 2248-2264. https://doi.org/10.17719/jisr.20164317789

Yazgi, B. et al. (2014). Impact of Characteristics of Origin and Destination Provinces on Migration: 1995-2000. European Planning Studies, 22, 1182-1198. https://doi.org/10.1080/09654313.2013.771620

Zukin, S. (1998). Urban Life Styles: Diversity and Standardization in Spaces of Consumption. Urban Studies, 35, 825-839. https://doi.org/10.1080/0042098984574

Submit or recommend next manuscript to SCIRP and we will provide best service for you:

Accepting pre-submission inquiries through Email, Facebook, LinkedIn, Twitter, etc. A wide selection of journals (inclusive of 9 subjects, more than 200 journals).

Providing 24-hour high-quality service

User-friendly online submission system

Fair and swift peer-review system

Efficient typesetting and proofreading procedure

Display of the result of downloads and visits, as well as the number of cited articles

Maximum dissemination of your research work

Submit your manuscript at: http://papersubmission.scirp.org/

Or contact cus@scirp.org 